

\title{
Perianal Crohn's disease results in fewer pregnancies but is not exacerbated by vaginal delivery
}

Amélie Grouin, Charlène Brochard, Laurent Siproudhis, Jean Lévêque, Jean-François Bretagne, Patrice Poulain, Guillaume Bouguen

\section{To cite this version:}

Amélie Grouin, Charlène Brochard, Laurent Siproudhis, Jean Lévêque, Jean-François Bretagne, et al.. Perianal Crohn's disease results in fewer pregnancies but is not exacerbated by vaginal delivery. Digestive and Liver Disease, 2015, 47 (12), pp.1021-1026. 10.1016/j.dld.2015.08.001 . hal-01187122

HAL Id: hal-01187122

https://hal-univ-rennes1.archives-ouvertes.fr/hal-01187122

Submitted on 21 Sep 2015

HAL is a multi-disciplinary open access archive for the deposit and dissemination of scientific research documents, whether they are published or not. The documents may come from teaching and research institutions in France or abroad, or from public or private research centers.
L'archive ouverte pluridisciplinaire HAL, est destinée au dépôt et à la diffusion de documents scientifiques de niveau recherche, publiés ou non, émanant des établissements d'enseignement et de recherche français ou étrangers, des laboratoires publics ou privés. 
Perianal Crohn's disease results in fewer pregnancies but is not exacerbated by vaginal delivery

Amélie Grouin ${ }^{1}$,M.D., Charlène Brochard ${ }^{2,3}$, M.D., Laurent Siproudhis ${ }^{2,3}$, M.D., Ph.D., Jean Leveque ${ }^{1}$, M.D., Ph.D., Jean-François Bretagne ${ }^{2}$, M.D., Ph.D., Patrice Poulain ${ }^{1}$, M.D., Ph.D., Guillaume Bouguen ${ }^{2,3}$ M.D., Ph.D.

${ }^{1}$ Department of Gynaecology \& Obstetrics, University Hospital of Rennes, and University of Rennes 1, 2 Rue Henri le Guilloux, 35000 Rennes, France

${ }^{2}$ Gastroenterology Unit, University Hospital of Pontchaillou, University of Rennes 1, 2 Rue Henri le Guilloux, 35000 Rennes, France

${ }^{3}$ INSERM U991, University of Rennes 1, 35000 Rennes, France

Short title: Deliveries and perianal Crohn's disease

\section{Correspondence to:}

Guillaume Bouguen

Service des Maladies de l'Appareil Digestif

2 Rue Henri le Guillou

35033 Rennes Cedex, FRANCE

Telephone (0033)-2-99-28-43-17 / Fax (0033)-2-99-28-41-89

Email: guillaume.bouguen@free.fr

Funding source: none

Word count: 
- abstract: 200

- manuscript (excluding the abstract, references, tables and figures): 2518 


\section{ABSTRACT}

Background. Despite a high prevalence of Crohn's disease in women of childbearing age, disease-related factors that may impact fertility and perianal Crohn's disease after delivery remain unclear.

Methods. Self-administered questionnaires related to childbirth were completed by women with Crohn's disease referred to a single gastroenterology unit. A survival analysis was performed for statistical purposes.

Results. A total of 184 patients were assessed, including 63 nulliparous women. The cumulative probabilities of having a child were $30 \%, 51 \%$ and $72 \%$ at the ages of 25 , 30 and 35 years, respectively. Women with colonic disease, prior abdominal surgery and perianal disease were less likely to experience childbirth. After a median followup of 165 weeks post-delivery, the cumulative probabilities of fistulizing perianal Crohn's disease occurrence were $8 \%, 12 \%$ and $21 \%$ at 1,2 and 5 years following childbirth, respectively. Contrary to a prior history of perianal Crohn's disease and colonic location, mode of delivery was not associated with perianal fistula. An episiotomy in the group of women with prior anal lesions did not result in a higher rate of fistula recurrence.

Conclusion. Perianal Crohn's disease is associated with fewer pregnancies, however perianal fistulas were less affected by obstetric events than their own natural history.

Keywords: deliveries, pregnancy, perianal Crohn's disease, Crohn's Disease 


\section{INTRODUCTION}

Crohn's disease $(C D)$ is a chronic inflammatory disease of the gastrointestinal tract that typically occurs in patients between 20 and 30 years, with a slightly higher rate of women in high-incidence cases areas. ${ }^{1}$ Thus, pregnancy is a common concern of women with CD of childbearing age.

Many studies have focused on the impact of disease activity on pregnancy and vice versa, but few have analysed both childbearing and delivery. ${ }^{2}$ Except for a decrease in fertility following an ileal pouch-anal anastomosis, the overall rates of fertility of women with inflammatory bowel disease (IBD) are similar to those observed in the general population..$^{2-4} \mathrm{~A}$ recent systematic review highlighted a decrease in fertility in women with CD related to voluntary childlessness. ${ }^{5}$

Aside from childbirth, both pregnant women and physicians have a fear of anal injuries related to delivery or Crohn's disease. ${ }^{6}$ Up to one third of patients with CD will experience either non-fistulizing perianal or fistulizing perianal Crohn's disease as a complication. ${ }^{7-9}$ Based on perianal CD outcomes and hypothetical damage of the perineum related to delivery, a recent ECCO consensus largely favoured caesarean section to limit vaginal delivery in cases of perianal CD or rectal involvement. ${ }^{10}$ However, these guidelines should be considered with caution because they are based on limited evidence. ${ }^{11-13}$ Moreover, previous retrospective series often lack careful perianal CD anal examinations and delivery details.

Given the concern of both patients and physicians, we aimed to identify diseaserelated factors that preclude onset of pregnancy and perianal CD outcomes following delivery in a large population of women with CD.

\section{METHODS}




\section{Study population}

All medical records of consecutive patients referred to a single gastroenterology unit over a seven-year period were reviewed. A centralized diagnostic index was used to identify women with a diagnosis of CD. The CD diagnosis was then confirmed based on radiological, endoscopic and/or histologic evidence. Only women with CD of a childbearing age (defined by age at referral between 15 and 45 years old) were included.

A self-administered questionnaire was mailed to the study population. In absence of an answer, a reminder was mailed to the non-responders. Questions specifically focused on Crohn's disease and childbirth and aimed to assess outcomes of each event over time. Because of the retrospective design of the study, we focused on childbirth rather than pregnancy as an irrevocable endpoint.

The following demographic and clinical characteristics of CD were extracted from the questionnaire and double-checked in electronic medical records of the patients: birth date, age at diagnosis, disease extent (including perianal involvement) and behaviour according to the Montreal classification, ${ }^{14}$ and previous history of anal or major abdominal surgery. For perianal $C D$, fistulizing perianal $C D$ was defined by an occurrence of a perianal abscess or any type of fistula that included a low- or highperianal fistula and recto-vaginal fistula. Non-fistulizing perianal CD was defined by the occurrence of anal ulcers and stenosis. ${ }^{7}$ Anal tags were not taken into account. Data were cross-referenced with those of a prospectively recorded database of perineal Crohn's disease.

Regarding obstetric outcomes, all deliveries were recorded. The following was reviewed for each delivery: gestational age, date, number and term of birth, least and greatest birth weights, mode of delivery (vaginal delivery or caesarean section), use 
of episiotomy, instrumental delivery (vacuum extraction or forceps), and occurrence of vaginal tears.

The study was approved by the Institutional Review Board of the university hospital of Rennes.

\section{Statistical analysis}

Quantitative variables were described as a median and percentile (I.Q.R. for Inter Quartile Range: $25 \%$ and $75 \%$ ). Categorical variables were presented as a number and percent of a cohort. Follow-up was determined by the duration between the date of investigation and date of completion of the last self-administered questionnaire. For childbirth, time to delivery was considered to begin at the mother birthdate and end at the date of the first delivery or last known follow-up. For fistulising perianal CD related to delivery, time to perianal $C D$ occurrence or recurrence was considered to begin at the last delivery and end at the event or last known follow-up. Two events were defined for analyses: (1) childbirth was defined by a delivery during the followup period; and (2) occurrence of perianal fistula by the onset of perianal fistula after the last delivery for women without perianal $C D$ before being pregnant or recurrence of perianal $C D$ after the last delivery for a patient with prior history of perianal $C D$. Events were assessed using a survival analysis. Cumulative probabilities of childbirth and perianal CD onset were estimated using a Kaplan Meier method. To identify predictive factors for each event, a univariate analysis was first performed using a log-rank test. To identify independent predictors of each events by multivariate analysis, all significant variables with $p$-values $<0.05$ in the log-rank test were retained and integrated into a Cox proportional hazards regression model. The results are shown as HRs with 95\% Cls. Statistical analyses were performed using JMP® Pro 10.0.0 software (Cary, North Carolina, USA). 


\section{RESULTS}

\section{Study population at referral}

Of the 329 women referred for Crohn's disease during the study period and of childbearing age, 2 patients had died $(0.6 \%), 105$ declined to complete the questionnaire (31.9\%), and 38 were lost to follow-up (11.5\%). Thus, our study population was composed of 184 patients (55.9\%). The characteristics of the study population regarding Crohn's disease and childbirth are listed in Table 1.

Of the 184 women, 121 had at least one delivery (65.7\%). Of these 121 patients, the median age at CD diagnosis was 27 years (range 12-57) and at first childbirth 25.5 years (range 18-37). The median age at the end of follow-up was 41 years (range 2661). According to the Montreal classification, ${ }^{14}$ disease locations were ileal, colic and ileocolic for 23 (19\%), 59 (48.7\%) and 36 women (29.7\%), respectively. Twenty-six of the 121 patients $(21.5 \%)$ had perianal CD prior to childbearing, and 51 women (42.1\%) developed perianal CD during follow-up. Major abdominal surgery was required for 39 women during the follow-up period (32\%).

Of the 63 childless women, median age at CD diagnosis was 19 years (range 3-44). Disease locations were ileal, colic and ileocolic for 10 (15.9\%), 20 (31.7\%) and 29 women (46\%), respectively. A total of 37 patients developed perianal CD (58.7\%). Major abdominal surgery was required for 32/63 women during follow-up (50.8\%). The characteristics of the pregnant women before delivery and the childless women are summarized in supplementary Table S1.

\section{Childbirth and associated factors}


Overall, the cumulative probabilities of a first delivery at the ages of 20, 25, 30 and 35 years were $14 \%, 30.2 \%, 50.8 \%$ and $71.6 \%$, respectively (Figure $1 \mathrm{~A}$ ).

The results of the univariate analysis indicated that the disease location, known diagnosis of Crohn's disease (prior to pregnancy), major abdominal surgery and perianal CD were associated with fewer childbirths as shown in Table 2.

The results of the multivariate analysis showed that the women with an L2 disease location (ileal), prior abdominal surgery or perianal Crohn's disease before childbearing were considerably less likely to become pregnant (Table 2 and Figure 1 panels B, C, D). The occurrence of pregnancy was similar regardless of the type of perianal $C D$ and location of abdominal surgery. Of the women with perianal CD before childbearing, the median age at the first childbirth was 27 , and the cumulative probabilities of having a delivery were $6.5 \%, 15.1 \%, 28.5 \%$ and $45.9 \%$ at the ages of $20,25,30$ and 35 years, respectively.

\section{Fistulizing perianal CD following delivery and associated factors}

Of the $121 \mathrm{CD}$ women who had undergone childbirth, 45 (including 12 women with perianal CD prior to pregnancy) developed a perianal fistula following delivery (37.2\%) after a median time of 165 weeks (range 28-485). Fistulizing perianal CD occurred following the first delivery in 16 women, second delivery in 21 women, third delivery in 5 women and fourth delivery in 3 women. The cumulative probabilities of fistula onset/recurrence after childbirth were $7.6 \%, 12 \%, 15.5 \%$ and $21.4 \%$ at $1,2,3$ and 5 years, respectively (Figure $2 \mathrm{~A}$ ).

The overall caesarean section and episiotomy rates for the patients are shown in Table 1. In the 45 women who developed fistulizing perianal CD after their last childbirth, the mode of delivery was a caesarean section for $24(53.3 \%)$ patients and 
vaginal delivery with episiotomy (with or without instrumental extraction) and/or perianal tears for $10(22.2 \%)$.

The women with L1 disease were less likely to develop a perianal fistula, as shown in Table 3. Conversely, L2 disease, colonic resection before childbearing and a diagnosis of perianal CD prior to pregnancy were associated with a higher risk of perianal fistula following childbirth. The occurrence of perianal fistula was not impacted by the mode of delivery, which included episiotomy, perianal tears and instrumental delivery. The multivariate analyses results showed that a previous diagnosis of perianal $C D$ and colonic $C D$ location independently increased the risk of perianal $C D$ occurrence (Figure $2 \mathrm{~B}$ and Table 3 ). The severity of perianal $\mathrm{CD}$ in the women following an episiotomy was similar to those without an episiotomy in regards to the need for anal surgery $(27 \%$ and $37 \%$, respectively, $p=0.23)$, number of anal surgeries after the diagnosis of fistulizing perianal $\mathrm{CD}(0.6$ and $0.8 \%$, respectively, $p=0.42)$ and need for a permanent stoma ( $8 \%$ and $7 \%$, respectively, $p=0.56)$. Focusing on vaginal delivery, the perianal CD occurrence after childbirth was not associated with an episiotomy (Figure 3A). The severity of perianal CD following an episiotomy was similar to those without an episiotomy concerning the need for anal surgery $(27 \%$ and $37 \%$, respectively, $p=0.23)$, number of anal surgeries after the diagnosis of fistulizing perianal $C D(0.6 \%$ and $0.8 \%$, respectively, $p=0.42)$ and need for a permanent stoma ( $8 \%$ and $7 \%$, respectively, $p=0.56)$. A total of 26 women had perianal $C D$ before delivery. Perianal $C D$ was in remission without active clinical lesions before delivery for 19 women. Seven women experienced active fistulizing disease during pregnancy. Of these 7 patients, 5 underwent $\mathrm{C}$-section, and 2 had a vaginal delivery without an episiotomy or perianal tears. At the end of the follow-up, 3 of the 7 women required a permanent stoma. These 3 women had a C-section. 
Based on the history of perianal CD before childbirth, the subgroup analysis did not find any difference in outcomes after an episiotomy (figure 3B and 3C). Similar results were observed for a vaginal delivery when the diagnosis of CD occurred after childbirth. During the follow-up, 22 patients developed a recto-vaginal fistula. Similarly, the mode of delivery did not affect the rate of rectovaginal fistula formation. The presence of a rectovaginal fistula was positively associated with the colonic location of $\mathrm{CD}(\mathrm{HR}=2.83$ [1.02-9.01], $\mathrm{p}=0.0442)$.

\section{DISCUSSION}

Pregnancy remains a challenging issue for both a treating physician and a woman with $C D$, a disease that may result in childlessness. ${ }^{5}$ The reasons for voluntary childlessness in women with CD remain unclear. Several patient-related factors have been suggested, such as a fear of disease outcomes during pregnancy, fear of IBD inheritance, fear of infertility and educational background. ${ }^{5,6,15,16}$ None of these studies took into account disease-related factors. We identified important factors related to $C D$ that directly impact the onset of childbirth. Surprisingly, a prior diagnosis of CD was not associated with childlessness. By contrast, abdominal surgery, colonic CD location and perianal CD before the onset of childbirth highly decreased the fertility in this population. Although, in some cases, surgery could decrease the fertility of women, both factors are known to be associated with a disabling course of CD. These results underline the possible influence of a physician's advice to delay conception because of the severity of $C D$, not the presence of CD itself. Fear of women could be another associated explanation: they previously experienced surgery for perianal $C D$ and knew its impact on quality-of-life and disability. 
One might argue that improved knowledge on CD outcomes during and after delivery may be a prerequisite to having children. Overall, the risk of perianal CD following delivery was low. Five years after delivery, about one fifth of women developed perianal $C D$. In the literature, the rate of perianal $C D$ after childbirth ranges from $0 \%$ to $67 \% .^{11,12,17,18}$ We did not restrict perianal CD occurrence within the two years of the post-partum to avoid misdiagnosis of late onset of perianal CD related to childbirth scars. None of factors related to childbirth were associated with the occurrence of fistulizing perianal CD by the univariate or the multivariate analyses. By contrast, the disease characteristics already known to increase the risk of perianal $\mathrm{CD}$, such as colonic disease or prior perianal $C D$, were associated with the occurrence of perianal CD.

The rate of caesarean sections was similar to that observed in previous studies ${ }^{12,18}$ and tended to be higher compared to the general population. A total of $39 \%$ of the women required a caesarean section compared to an overall rate of $20.7 \%$ in a referral hospital in France. ${ }^{19}$ Importantly, a caesarean section did not protect against the onset or recurrence of perianal CD in the present study, which highlights the high risk of perianal $C D$ relapse and low risk of perianal $C D$ onset regardless of the mode of delivery. Importantly, a vaginal delivery with or without perineal tears or an episiotomy was not associated with the occurrence of perianal CD after delivery, even in the patients with a prior history of perianal lesions. This is in line with recent data from the Netherlands that did not show any association between perianal CD and mode of delivery. ${ }^{18}$ Moreover, the authors underlined the overall increased risk for complications following a caesarean section. ${ }^{18}$ In a retrospective study from Manitoba, unless there was a high rate of perianal trauma related to vaginal delivery, the rate of active perianal CD following childbirth remained low. ${ }^{12}$ Brandt et al 
observed that $18 \%$ of perianal CD onset following vaginal delivery was within 2 months of delivery. However, the authors admitted methodological limitations, particularly the lack of data verification. Additionally, no CD characteristics were taken into account. ${ }^{11}$ Finally, the present study underlined the link between perianal $C D$ and $C D$ characteristics rather than obstetric choice.

Our study results should be interpreted with caution for several reasons. First, this is a retrospective study based on self-administered questionnaires. While CD data were double-checked in the chart of the patients (which were prospectively recorded, especially regarding perianal CD), some data regarding the pregnancy and delivery could not be verified. To overcome this limitation, we excluded all subjective data from the analyses, such as the reason for the mode of delivery. This referral centre study introduces a recruitment bias with severe CD more able to develop perianal lesions. Finally, the population of childless women was younger and more severe, as underlined by the rate of perianal $C D$ and abdominal surgery. That said, the main strengths of this work are its sample size, long duration of follow-up, choice of survival analysis to limit impact of age, follow-up duration and systematic assessment of perianal $C D$ in an IBD unit. Most of the data related to IBD were recorded in a prospective database using recommended classifications and validated scales, such as the Montreal classification of the luminal disease and different anal phenotypes. In conclusion, perianal CD and abdominal surgery severely affect fertility. The age onset of first childbirth was delayed by approximately 5 to 7 years. By contrast, the mode of delivery in childbearing women did not appear to impact the natural history of perineal Crohn's disease, which should reassure mothers and physicians following vaginal delivery. 


\section{Conflict of interest:}

GB received lecture fees from Abbvie, Ferring and MSD, LS received lecture Fees from Abbvie, JFB received lecture fees from Abbvie. AG, JL and PP déclares no conflict of interest. 


\section{References}

1. Cosnes J, Gower-Rousseau C, Seksik P, et al. Epidemiology and natural history of inflammatory bowel diseases. Gastroenterology 2011;140:1785-94.

2. Mahadevan U, Cucchiara S, Hyams JS, et al. The London Position Statement of the World Congress of Gastroenterology on Biological Therapy for IBD with the European Crohn's and Colitis Organisation: pregnancy and pediatrics. Am J Gastroenterol 2011;106:214-23.

3. Ording Olsen K, Juul S, Berndtsson I, et al. Ulcerative colitis: female fecundity before diagnosis, during disease, and after surgery compared with a population sample. Gastroenterology 2002;122:15-9.

4. Waljee A, Waljee J, Morris AM, et al. Threefold increased risk of infertility: a meta-analysis of infertility after ileal pouch anal anastomosis in ulcerative colitis. Gut 2006;55:1575-80.

5. Tavernier N, Fumery M, Peyrin-Biroulet L, et al. Systematic review: fertility in non-surgically treated inflammatory bowel disease. Aliment Pharmacol Ther 2013;38:847-53.

6. Marri SR, Ahn C, Buchman AL. Voluntary childlessness is increased in women with inflammatory bowel disease. Inflamm Bowel Dis 2007;13:591-9.

7. Bouguen G, Siproudhis L, Bretagne JF, et al. Nonfistulizing perianal Crohn's disease: clinical features, epidemiology, and treatment. Inflamm Bowel Dis 2010;16:1431-42.

8. Mahadev S, Young JM, Selby W, et al. Quality of life in perianal Crohn's disease: what do patients consider important? Dis Colon Rectum 2011;54:579-85. 
9. Sandborn WJ, Fazio VW, Feagan BG, et al. AGA technical review on perianal Crohn's disease. Gastroenterology 2003;125:1508-30.

10. Van Assche G, Dignass A, Reinisch W, et al. The second European evidencebased Consensus on the diagnosis and management of Crohn's disease: Special situations. J Crohns Colitis 2010;4:63-101.

11. Brandt LJ, Estabrook SG, Reinus JF. Results of a survey to evaluate whether vaginal delivery and episiotomy lead to perineal involvement in women with Crohn's disease. Am J Gastroenterol 1995;90:1918-22.

12. Ilnyckyji A, Blanchard JF, Rawsthorne $P$, et al. Perianal Crohn's disease and pregnancy: role of the mode of delivery. Am J Gastroenterol 1999;94:3274-8.

13. Ong JP, Edwards GJ, Allison MC. Mode of delivery and risk of fecal incontinence in women with or without inflammatory bowel disease: questionnaire survey. Inflamm Bowel Dis 2007;13:1391-4.

14. Satsangi J, Silverberg MS, Vermeire S, et al. The Montreal classification of inflammatory bowel disease: controversies, consensus, and implications. Gut 2006;55:749-53.

15. Mountifield R, Bampton P, Prosser R, et al. Fear and fertility in inflammatory bowel disease: a mismatch of perception and reality affects family planning decisions. Inflamm Bowel Dis 2009;15:720-5.

16. Selinger CP, Eaden J, Selby W, et al. Inflammatory bowel disease and pregnancy: lack of knowledge is associated with negative views. J Crohns Colitis 2013;7:206-13.

17. Beniada A, Benoist G, Maurel J, et al. Inflammatory bowel disease and pregnancy: report of 76 cases and review of the literature. J Gynecol Obstet Biol Reprod (Paris) 2005;34:581-8. 
18. Smink M, Lotgering FK, Albers L, et al. Effect of childbirth on the course of Crohn's disease; results from a retrospective cohort study in the Netherlands. BMC Gastroenterol 2011;11:6.

19. Mangin M, Ramanah R, Aouar Z, et al. [Operative delivery data in France for 2007: results of a national survey within teaching hospitals]. J Gynecol Obstet Biol Reprod (Paris) 2010;39:121-32. 


\section{FIGURE LEGENDS}

\section{Figure 1:}

Panel A. Cumulative probabilities of first childbirth

Panels B-D. Kaplan-Meier analysis of first childbirth according to the predictors identified at multivariate analysis

Panel B. Disease location (HR [L2] 0.50, 95\% Cl [0.31-0.85], $p=0.01)$

Panel C. Abdominal surgery prior to childbirth $(\mathrm{HR}=0.19,95 \% \mathrm{Cl}[0.01-0.36], p<$ $0.0001)$

Panel D. Perianal Crohn's disease prior to childbirth $(\mathrm{HR}=0.31,95 \% \mathrm{Cl}[0.20-0.49]$, $\mathrm{p}<0.0001)$

CD, Crohn's disease; HR, Hazard Ratio; L1, ileal location; L2, colic location; L3, ileocolic location.

\section{Figure 2:}

Panel A. Cumulative probability of perianal Crohn's disease (perianal CD) after childbirth

Panel B. Kaplan-Meier analysis according to perianal Crohn's disease diagnosed before childbearing $(\mathrm{HR}=2.82 \mathrm{Cl} 95[1.37-4.5], \mathrm{p}=0.0057$

Panel C. Kaplan-Meier analysis according to Crohn's disease location (HR=3.32 Cl95[1.28-11.31], $p=0.01)$.

CD, Crohn's disease; HR, Hazard Ratio.

\section{Figure 3:}


Panel A. Perianal Crohn's disease following an episiotomy in the whole study population (log-rank, p=0.06)

Panel B. Perianal Crohn's disease in women without perianal Crohn's disease before childbearing (log-rank, $p=0.06)$

Panel C. Perianal Crohn's disease in women with prior history of perianal Crohn's disease (log-rank, $p=0.42)$.

$\mathrm{CD}$, Crohn's disease. 
Table 1. Demographic and laboratory features of the patients with type 1 gastric carcinoid (GC1), non recurrent GC1, at the time of first diagnosis, and recurrent $\mathrm{GC1}$, at the moment of first recurrence. There were no significant differences among recurrent and non-recurrent GC1 patients.

\begin{tabular}{|c|c|c|c|}
\hline \multirow{3}{*}{ Parameter } & \multirow[t]{2}{*}{ GC1 } & \multirow[t]{2}{*}{ Non recurrent GC1 } & \multirow[t]{3}{*}{ Recurrent GC1 } \\
\hline & & & \\
\hline & $(n=25)$ & $(n=13)$ & \\
\hline Gender (M, \%) & $5(20)$ & $1(0.7 \%)$ & $4(33 \%)$ \\
\hline Age [median (range), years] & $62(35-82)$ & $61(35-82)$ & $65(51-80)$ \\
\hline Anti-parietal cell antibodies & $20(80 \%)$ & $9(69 \%)$ & $11(92 \%)$ \\
\hline BMI [median (range), $\mathrm{kg} / \mathrm{m}^{2}$ ] & $22(18-35)$ & $22(18-35)$ & $22(20-23)$ \\
\hline Gastrin [median (range), pg/mL] & 899 (139-2820) & $894(340-2110)$ & $802(171-2003)$ \\
\hline Chromogranin A [median (range), U/L] & $44(15-230)$ & $57(16-230)$ & $33(14-72)$ \\
\hline Follow-up [median (range), months] & $77(6-165)$ & $58(6-165)$ & $94(42-165)$ \\
\hline GC1 Diameter [median (range), mm] & $6(2-30)$ & $8(2-14)$ & $4(1-10)$ \\
\hline GC1 Grade (Ki-67 <2/Ki-67 2-20) & $23 / 2$ & $11 / 2$ & $12 / 0$ \\
\hline ECL hyperplasia $[n,(\%)]$ & & & \\
\hline Absent & $4(16)$ & $1(8)$ & $1(8)$ \\
\hline Simple & $1(4)$ & $1(8)$ & $3(25)$ \\
\hline Linear & $2(8)$ & $2(15)$ & $2(17)$ \\
\hline Micronodular & $10(40)$ & $7(54)$ & $4(33)$ \\
\hline
\end{tabular}


Macronodular

Intestinal metaplasia

Other tumors

[n, (\%)]
$8(32)$

$18(72)$

$5(20)$

\begin{tabular}{|c|c|}
\hline $2(15)$ & $2(17)$ \\
\hline $9(69)$ & $12(100)$ \\
\hline $3(23)$ & $2(17)$ \\
\hline
\end{tabular}

GC1, type 1 gastric carcinoid; BMI, body mass index; ECL, enterochromaffin-like cells 
Table 2. Association between chronic liver disease mortality (overall and by etiology) and education level: Odds Ratio with 95\% Confidence Interval estimated by conditional logistic regression. Veneto region, 2011-2013.

\begin{tabular}{|l|c|c|c|}
\hline & & $\begin{array}{c}\text { Middle vs. } \\
\text { High/college }\end{array}$ & $\begin{array}{c}\text { Primary vs. } \\
\text { High/college }\end{array}$ \\
\hline Males & $\begin{array}{c}\text { Number of } \\
\text { deaths }\end{array}$ & OR (CI) & OR (CI) $^{\#}$ \\
\hline All liver diseases & 2,023 & $1.31(1.12-1.53)$ & $1.37(1.18-1.60)$ \\
\hline Alcohol-related & 544 & $1.32(0.98-1.77)$ & $1.62(1.22-2.14)$ \\
\hline Virus-related & 323 & $1.28(0.93-1.76)$ & $0.75(0.53-1.05)$ \\
\hline NVNA* & 1,198 & $1.36(1.10-1.69)$ & $1.49(1.22-1.82)$ \\
\hline Females & & & $1.72(1.29-2.30)$ \\
\hline All liver diseases & 768 & $1.35(0.99-1.84)$ & $1.72)$ \\
\hline Alcohol-related & 141 & $1.24(0.63-2.46)$ & $2.34(1.23-4.45)$ \\
\hline Virus-related & 171 & $1.30(0.69-2.44)$ & $1.24(0.69-2.22)$ \\
\hline NVNA* & 466 & $1.41(0.94-2.12)$ & $1.77(1.22-2.59)$ \\
\hline
\end{tabular}

${ }^{\#}$ Odds Ratio with 95\% Confidence Interval

NVNA, non-virus/non-alcohol related 
Table 3 Factors associated with fistulizing perianal Crohn's disease occurrence after childbirth

\begin{tabular}{|c|c|c|}
\hline & $\begin{array}{c}\text { UNIVARIATE } \\
\text { ANALYSIS }\end{array}$ & MULTIVARIATE ANALYSIS \\
\hline VARIABLES & p-value & HR [95\% CI], p-value \\
\hline Age at CD diagnosis - & 0.516 & \\
\hline Montreal classification & & \\
\hline Montreal A1 $(<16)$ & 0.80816 & \\
\hline Montreal A2 (17-39) & 0.7988 & \\
\hline Montreal A3 (>39) & 0.7216 & \\
\hline Montreal L1 (ileal) & 0.0168 & reference \\
\hline Montreal L2 (colic) & 0.0079 & $3.32[1.28-11.31], 0.01$ \\
\hline Montreal L3 (ileocolic) & 0.3051 & $1.82[0.60-6.73], 0.29$ \\
\hline Diagnosis of CD before childbirth & 0.3689 & \\
\hline Abdominal surgery prior to childbirth & 0.2002 & \\
\hline Ileal resection & 0.9529 & \\
\hline Colonic resection & 0.0176 & 2.43 [0.66-7.19], 0.16 \\
\hline Perianal CD prior childbirth & $<0.0001$ & $2.82[1.37-4.5], 0.0057$ \\
\hline Number of childbirths per patient & 0.8229 & \\
\hline Birth Weight & & \\
\hline Lowest & 0.9025 & \\
\hline Highest & 0.2992 & \\
\hline Mode of delivery & & \\
\hline Caesarian section & 0.1076 & \\
\hline Episiotomy & 0.0662 & \\
\hline
\end{tabular}

A, Age; CD, Crohn's Disease; IQR, Interval Quartile Range; L, location; HR, hazard ratio; CI, confidence interval 


\section{Conflict of interest:}

GB received lecture fees from Abbvie, Ferring and MSD, LS received lecture Fees from Abbvie, JFB received lecture fees from Abbvie. AG, JL and PP déclares no conflict of interest.

Funding: none 


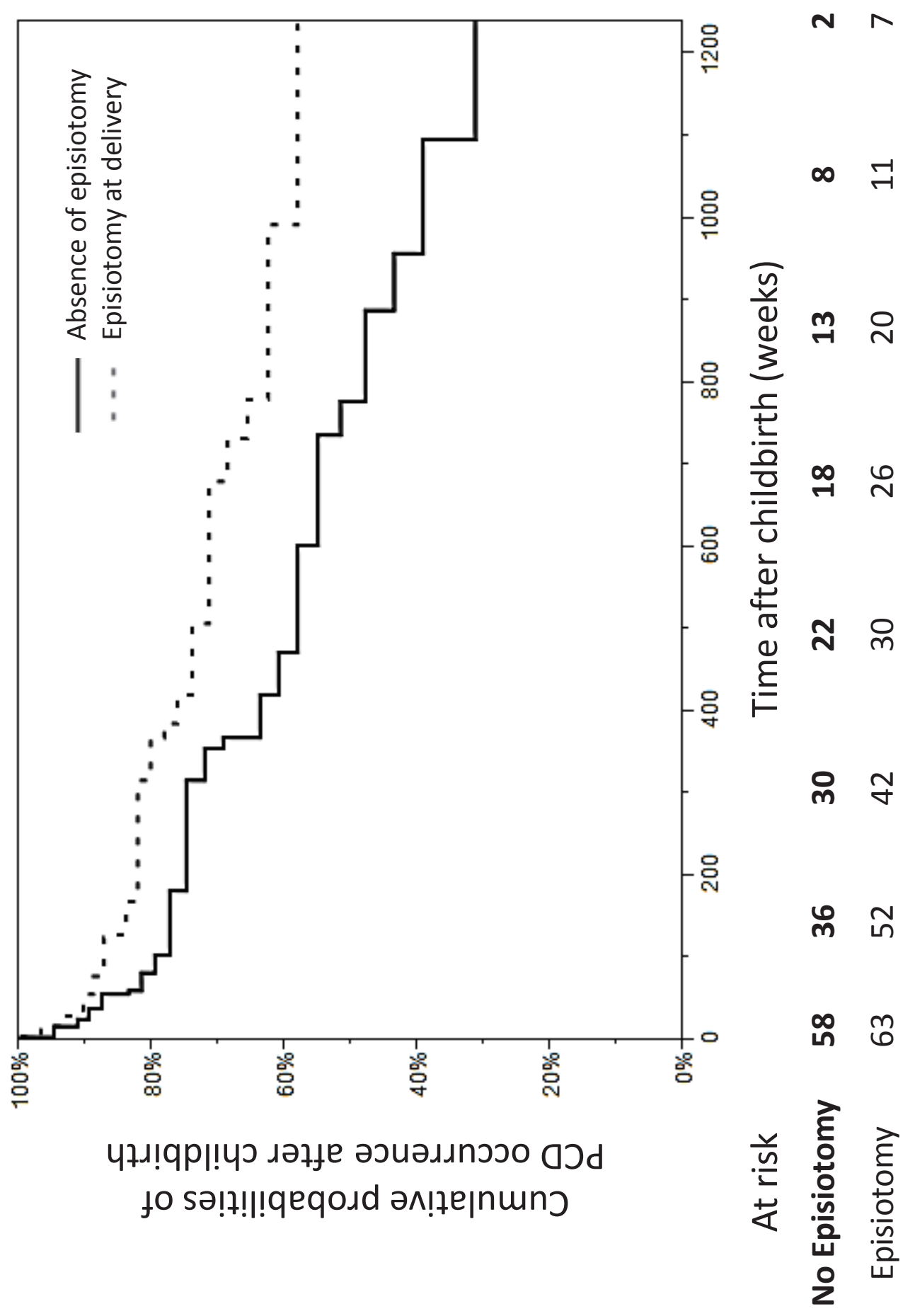




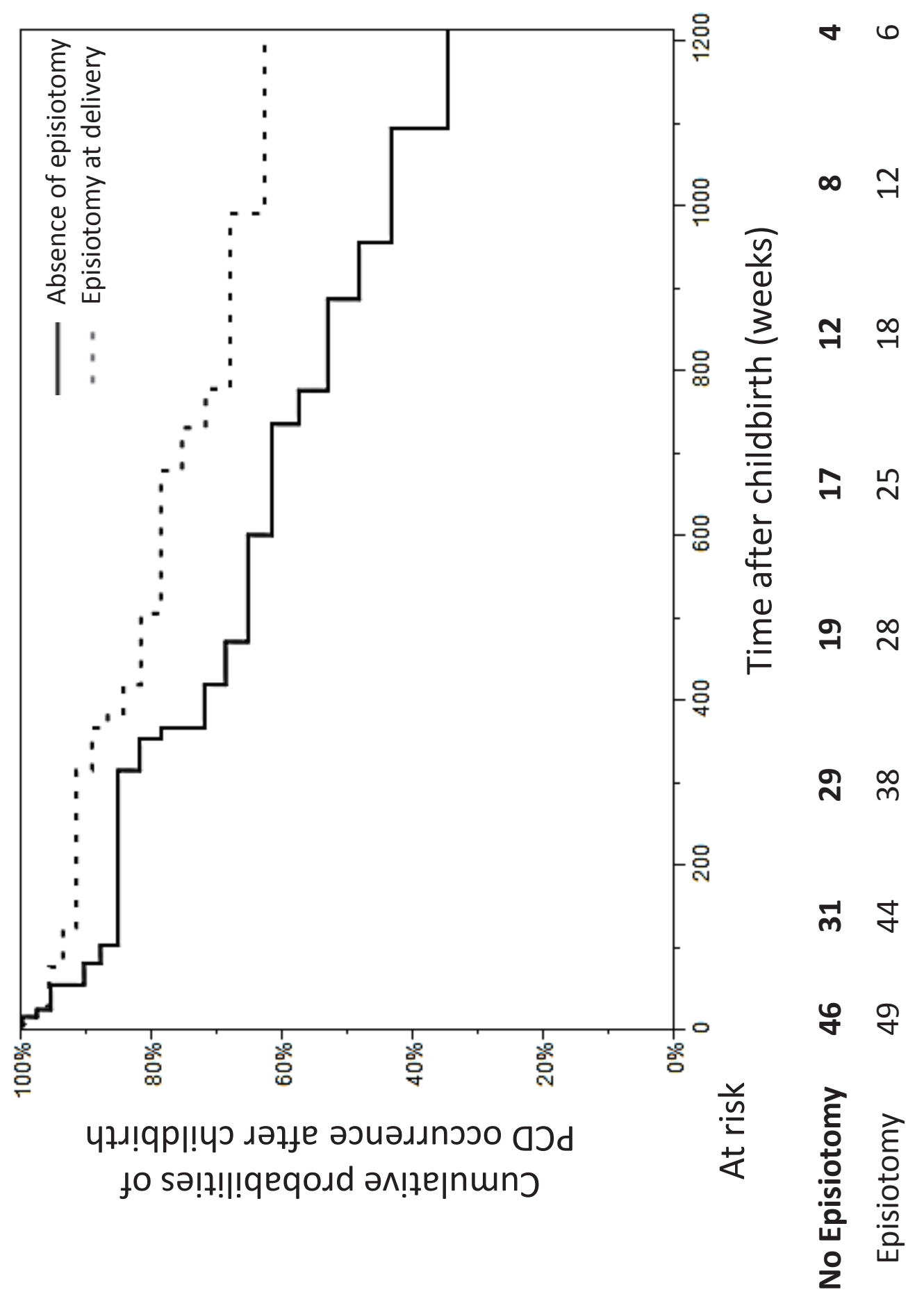




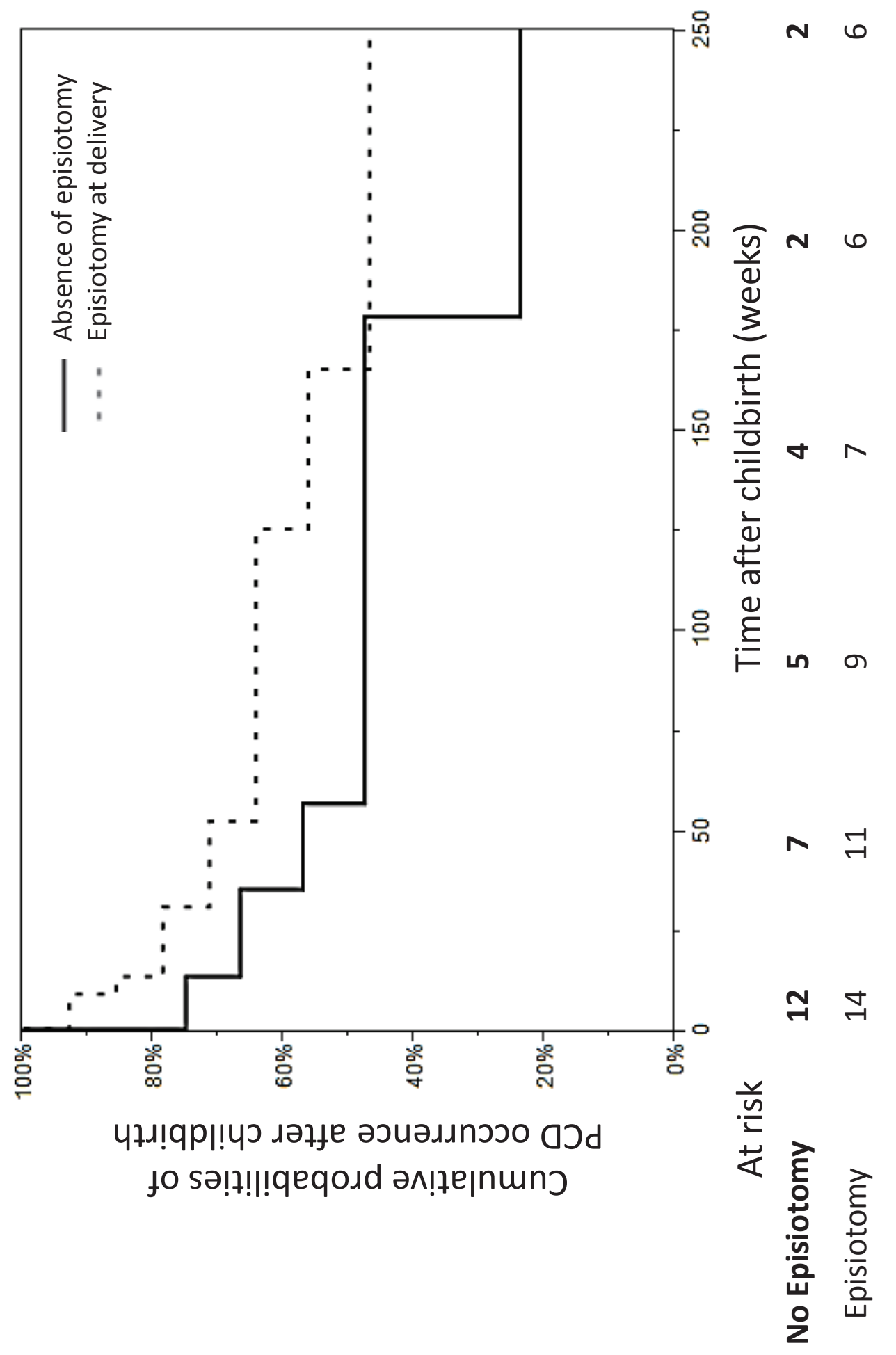




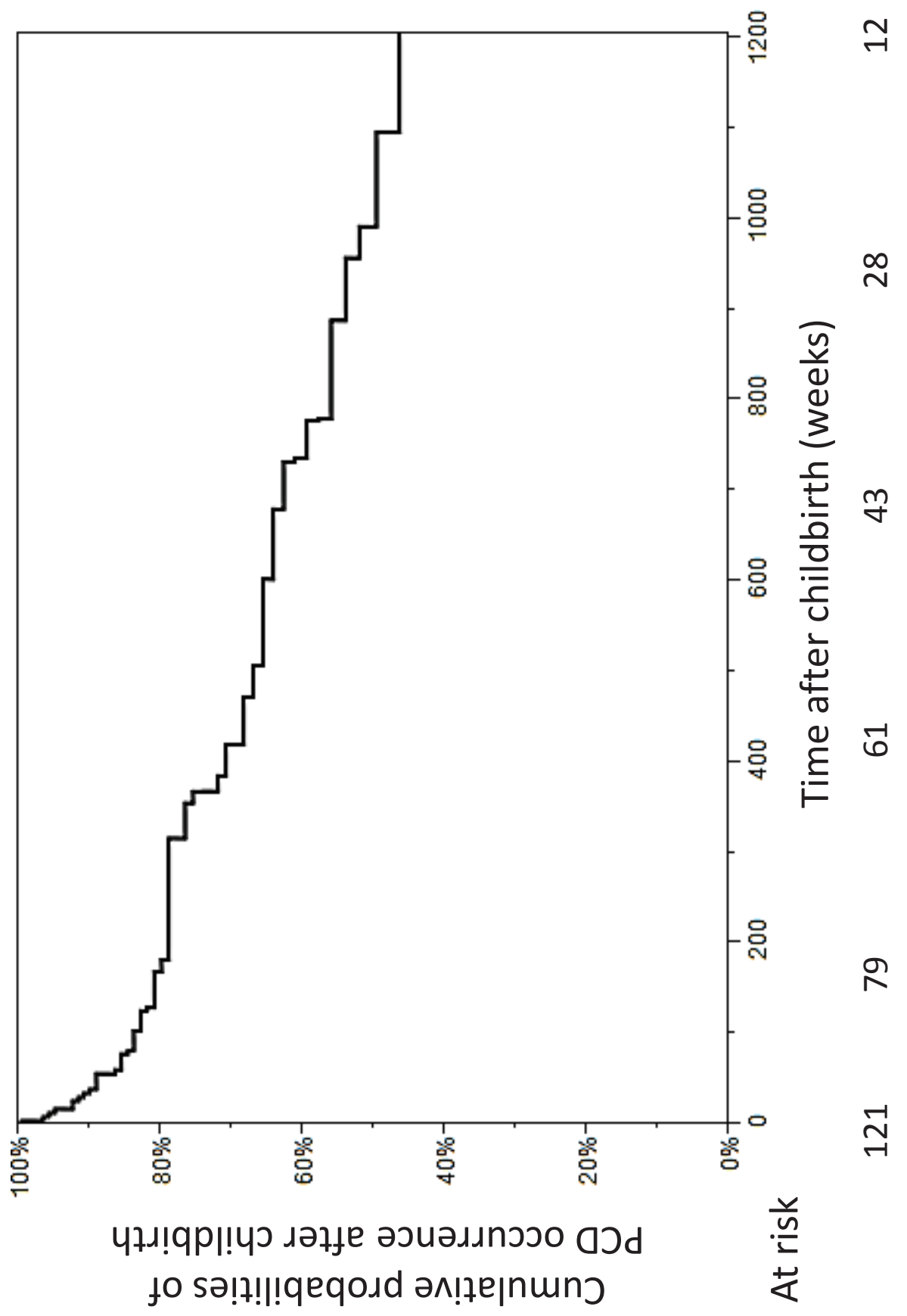




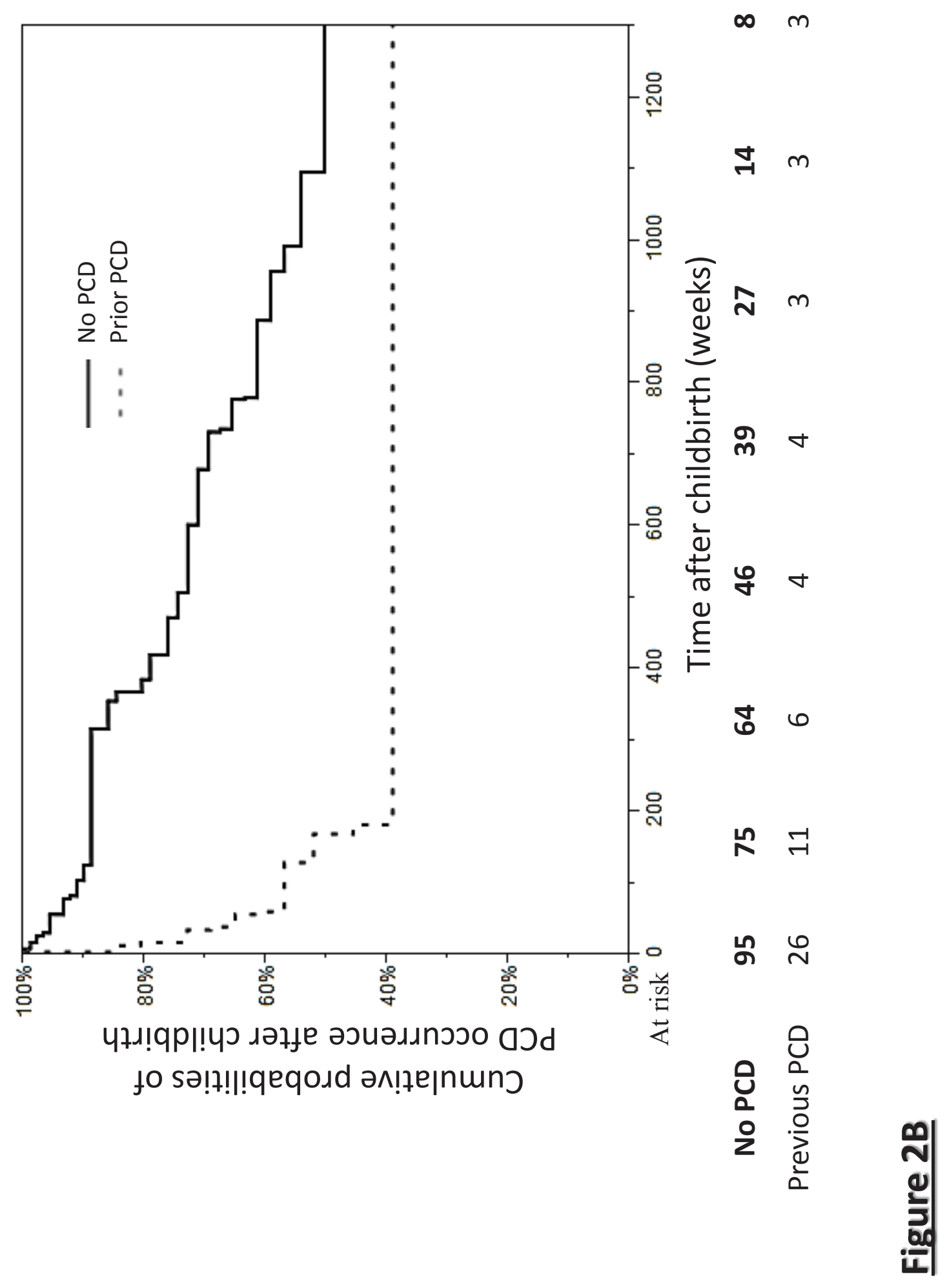









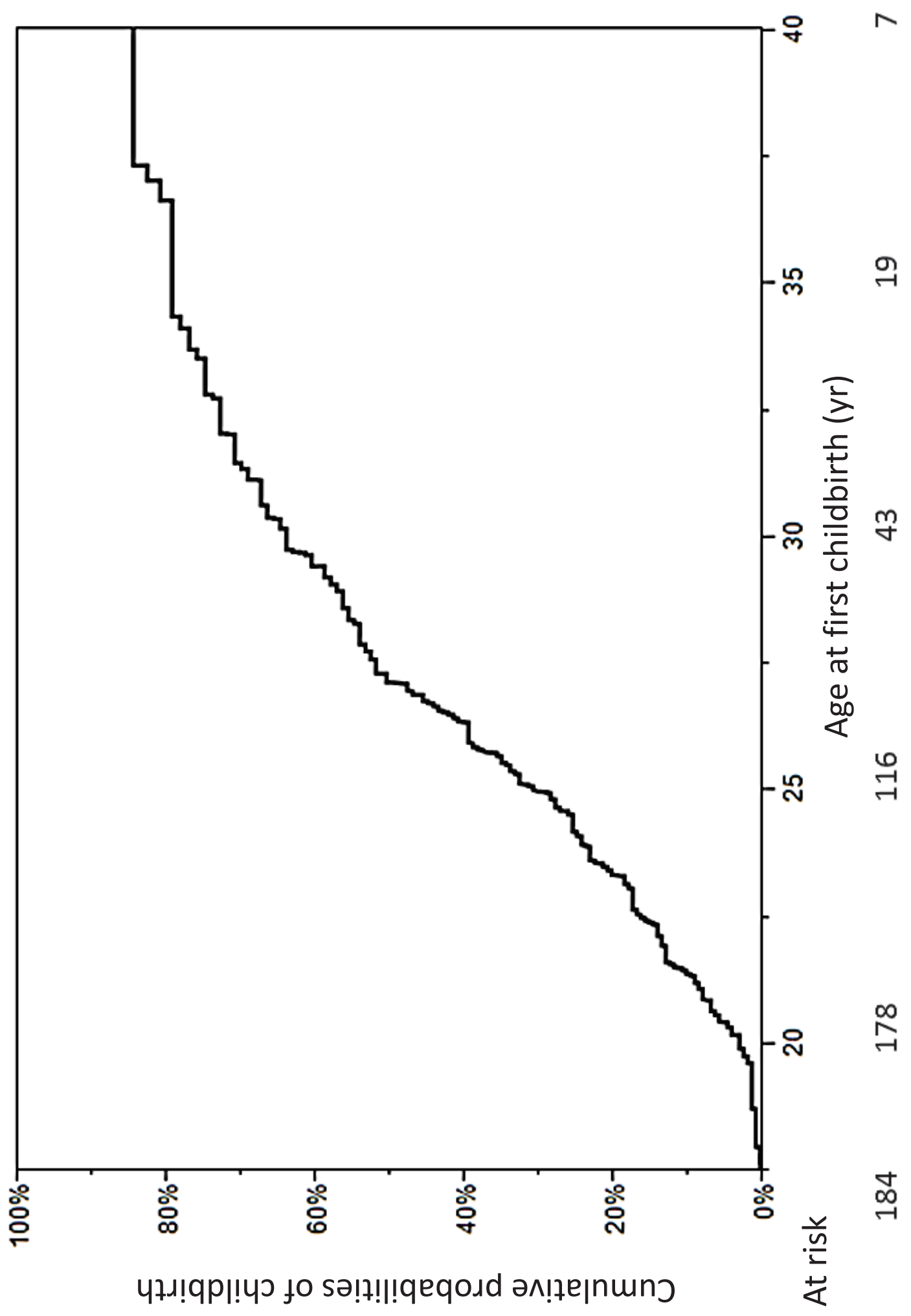




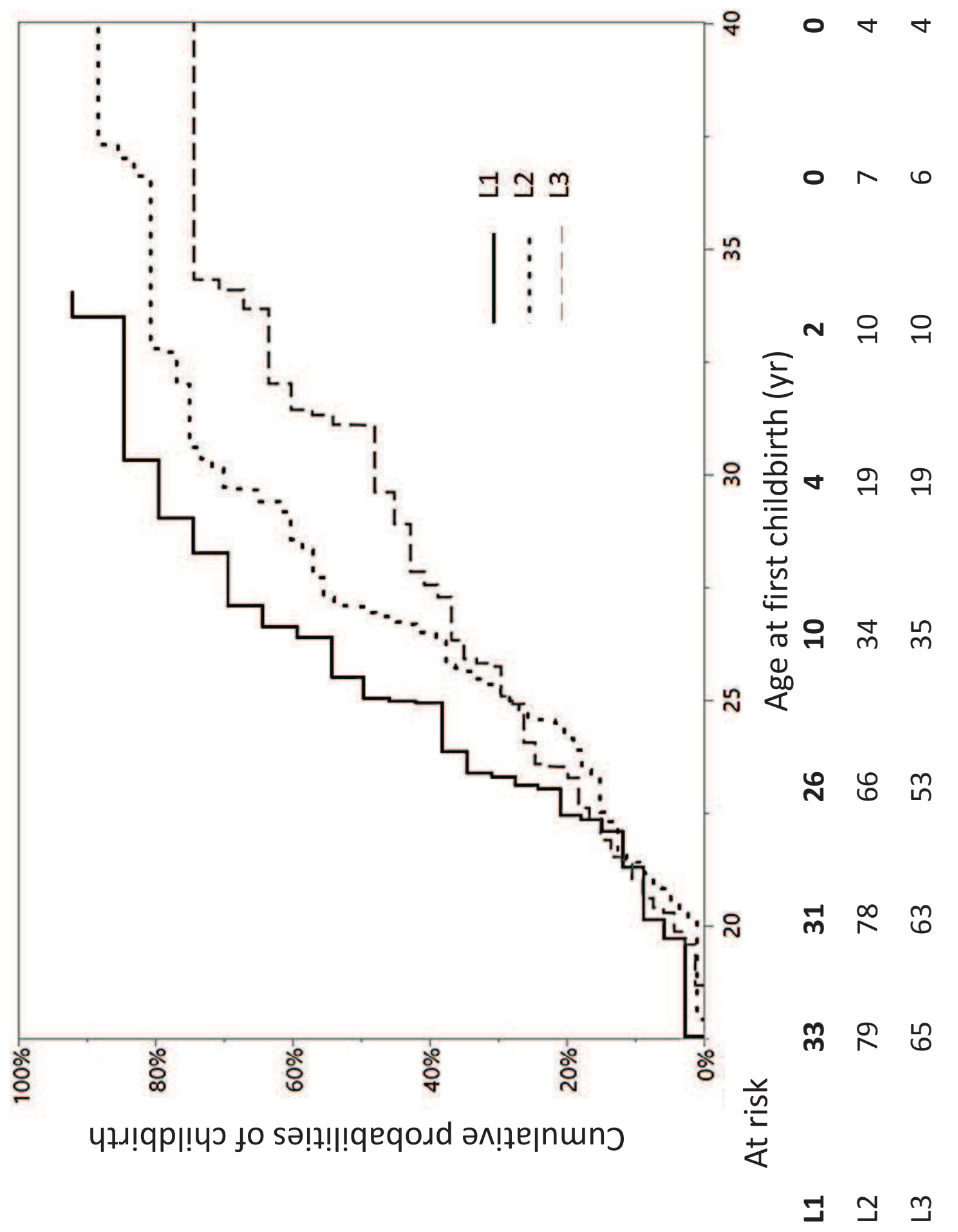









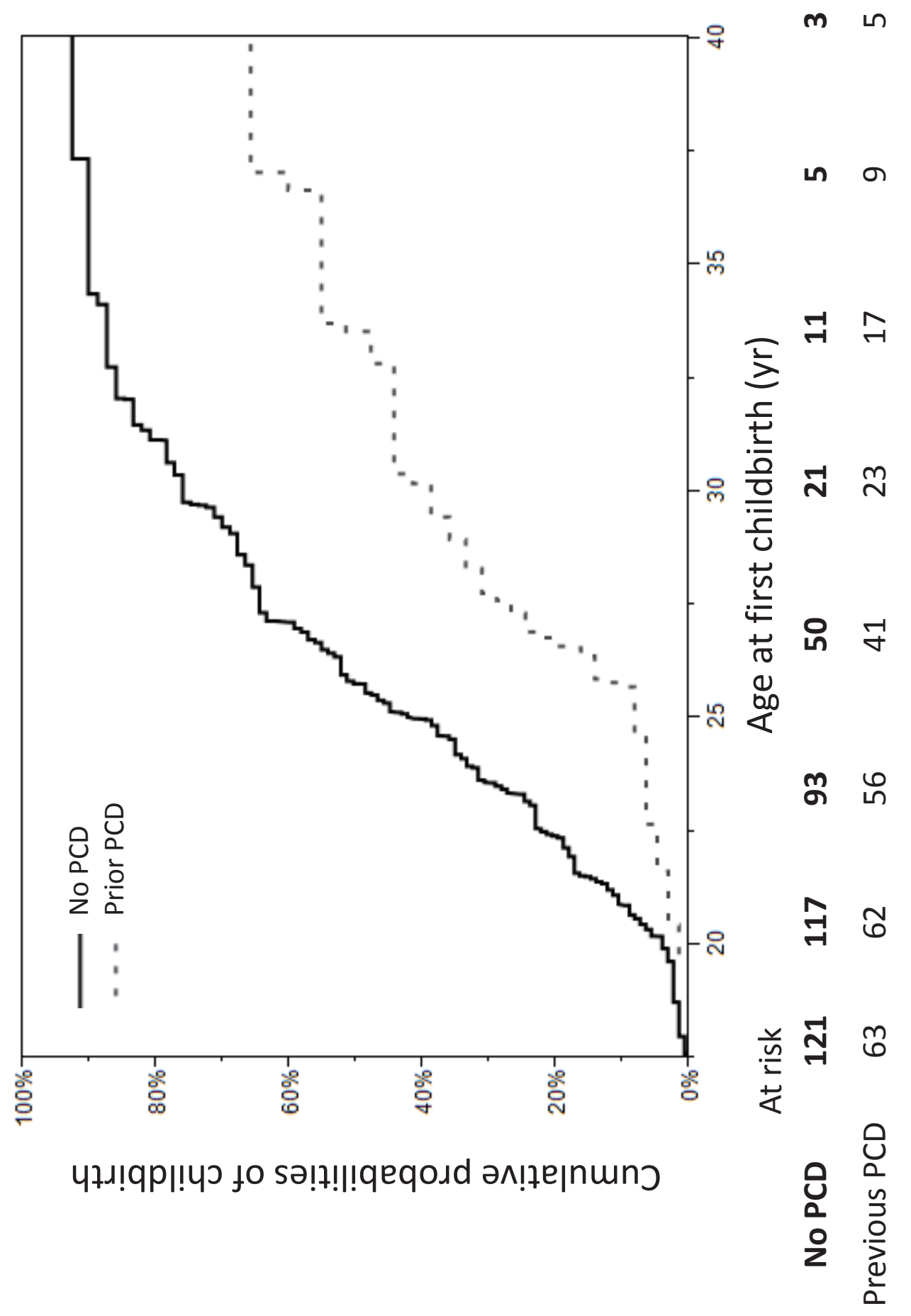

